\title{
Issues Associated with Combustibility Classification: Alternate Test Concepts
}

\author{
FREDERIC B. CLARKE
}

Benjamin/Clarke Associates

Arlington, Virginia, USA

\begin{abstract}
The cone calorimeter (ASTM E1354/ISO 5660) has been suggested as a replacement or alternate for ASTM/ E136/ISO 1182 in classifying the combustibility of materials. While the cone offers several advantages over the existing test, this paper identifies two potentially serious shortcoming as well: (1)the sensitivity of measured values to sample thickness and orientation, and (2) poor reproducibility at low levels of heat release which characterize noncombustibility. The first of these difficulties makes the results dependent on the scenario in which the material is to be employed; the second issue makes it difficult to obtain reliable measurements for combustibility classification. It is proposed instead that combustibility be classified on the basis of bomb calorimetry, ASTM D2015/ISO 1716. Like the cone, bomb calorimetry provides a continuous scale of combustibility, but it is also scenario-independent, more reproducible and gives rise to combustibility classifications which are directly relatable to those in current use.
\end{abstract}

Keywords: combustibility; cone calorimeter; bomb calorimeter; non-combustible

\section{INTRODUCTION}

\section{A. Scope}

This paper explores the most important issues associated with classifying the combustibility of materials and products by means other than the furnace-based methods now in regulatory use in North America (ASTM E136) ${ }^{1}$ and Europe (ISO1182) ${ }^{2}$. The cone calorimeter (ASTM E1354; ISO 5660) $)^{3,4}$, which has been proposed for this purpose, has been suggested by its proponents to offer several advantages:

- It is not a pass/fail test like E136/ISO 1182 but rather expresses results on a continuous numerical scale. 
- Its numerical results have physical significance and can be used as part of a hazard assessment procedure, such as mathematical modeling.

- It is physically more realistic because it can often test composites in their assembled form instead of requiring that they be homogenized.

The cone is in use on a trial basis to classify degrees of combustibility in the Canadian Building Codes.

The authors agree that ASTM E136/ISO 1182, tests which were developed over 50 years ago, have shortcomings which make them candidates for replacement. The authors take the view, however, that non-combustibility should remain a scenario-independent means of telling whether something will burn. At present, when a material or product is classified as non-combustible (NC), the intended meaning is precisely that: no matter what its physical form, whether exposed or concealed, whether used as intended or not, an NC material will virtually never produce more heat than the test indicates. This feature makes it scenarioindependent. It is not necessary to know the circumstances of use to predict how much it will contribute to the buildup of heat and the thermal hazard; it will contribute very little in any situation.

Retaining this feature requires that any acceptable replacement for E136/ISO R1182 determine the maximum possible amount of heat produced: the cone calorimeter does not do so. Results vary depending upon the thermal properties of the sample and its thickness. The cone, moreover, is ill-suited for reliably detecting the low levels of heat which noncombustible materials produce. In the following sections, these points are expanded and a proposal for combustibility classification is advanced based on the heat of combustion, a scalar quantity which eliminates the flaws of a pass/fail approach but, because it is also a thermodynamic quantity, still preserves scenario-independence. The compilations published by ASTM, ISO and NFPA all include similar standard methods for determining heat of combustion using an oxygen bomb calorimeter.

\section{A Comparison of Calorimeter Test Characteristics: the Oxygen Bomb, the E136 Muffle Furnace and the Cone}

\section{A.. The Oxygen Bomb}

The Oxygen Bomb, which appears in essentially the same form as ASTM D2015 ${ }^{6}$, ISO $1716^{7}$ and NFPA $259^{8}$, is the calorimeter in its classical form, in which a finely-divided sample is placed in a heavy-walled steel pressure vessel (the "bomb"), several atmospheres of pure oxygen or a chemical oxidizer are added, the sample is ignited and the resulting temperature rise carefully measured. Because complete combustion is assured, the heat produced when the sample burns is all there is: the total heat of combustion, or the "potential heat" of the material/product. 


\section{B. The Muffle Furnace}

In ASTM E136 and ISO 1182, a finely-divided sample is placed in a well-ventilated compartment in a muffle furnace heated to $750^{\circ} \mathrm{C}$. The test is continued until the interior of the sample reaches essentially the same temperature as the furnace. If the temperature exceeds that of the furnace by more than a small amount, then the sample fails, i.e., it cannot be classified noncombustible -- because combustion was required to produce the temperature rise. Here again, complete combustion is virtually assured, but in this case it is accomplished by requiring that the interior of the sample reach $750^{\circ} \mathrm{C}$. It would not be a particularly good means of detecting anything but small amounts of heat, because it is an open system with opportunities for heat loss. This is why it is a pass/fail test: it is sensitive and gives reliable data over only a narrow range -- a range too narrow to encompass anything but nearly refractory materials.

\section{The Cone Calorimeter}

In the cone calorimeter, ASTM E1354 and ISO 5660, the sample is not pulverized but is tested in whatever form it is used in practice. The sample is supported horizontally and is heated radiantly by a cone-shaped heater above it, which can be set at any desired level. The irradiated sample is ignited and all of the effluent from the resulting combustion is collected. In this case, temperature is not measured; instead, the rate at which heat is released is calculated from the flow of oxygen-depleted air in the exhaust. The rate at which heat is produced by the burning sample depends upon the setting of the radiant heater.

As proposed for combustibility classification purposes ${ }^{5,9}$, the test is carried out at a single, relatively high, flux level -- 50 or $75 \mathrm{~kW} / \mathrm{m}^{2}$-- and has a time limit of 15 minutes, after which no more data are collected. The total amount of heat produced may or may not be all that the sample contains, it is just whatever is produced during the test period. If the interior of the sample does not get hot enough -- or hot enough soon enough -- burning will not be complete before the test is over. For that reason, heat measurements on the cone calorimeter are never greater -- and almost always less -- than those on the same sample when it is evaluated in the oxygen bomb.

\section{Comparative Performance Data: Previous Work}

Because the muffle furnace tests do not provide scalar data as results, they are the subject of little comparative work. Some work has been done, however, in the case of the bomb and the cone. Hoover has compared the heats of combustion, as measured in both the bomb and the cone, for a series of cable samples ${ }^{10}$. It was found that the results from the cone depended heavily on imposed flux, as expected, but that even at high flux $\left(75 \mathrm{~kW} / \mathrm{m}^{2}\right)$, the cone values could be as little as half of those determined in the bomb. 
Houser ${ }^{11}$ has carried out a series of cone calorimeter measurements on building materials following the proposed procedure for combustibility classification ( 3 trials; horizontal orientation; $75 \mathrm{~kW} / \mathrm{m}^{2}$ imposed flux; 15 minute test period) ${ }^{9}$. For many of the materials having low levels of combustibility, the measurements showed poor reproducibility as can be seen from Figures 1 and 2, which are derived from Houser's data. They show the relative reproducibility (the reproducibility ${ }^{12}$ divided by the mean value of the measurement) plotted as a function of peak 60 -second heat release rate and total heat content respectively. Values of relative reproducibility above unity mean that the expected uncertainty in the measurement is larger than the magnitude of the measurement itself. At higher rates of heat release and total heat, the relative reproducibility declines to more manageable levels.

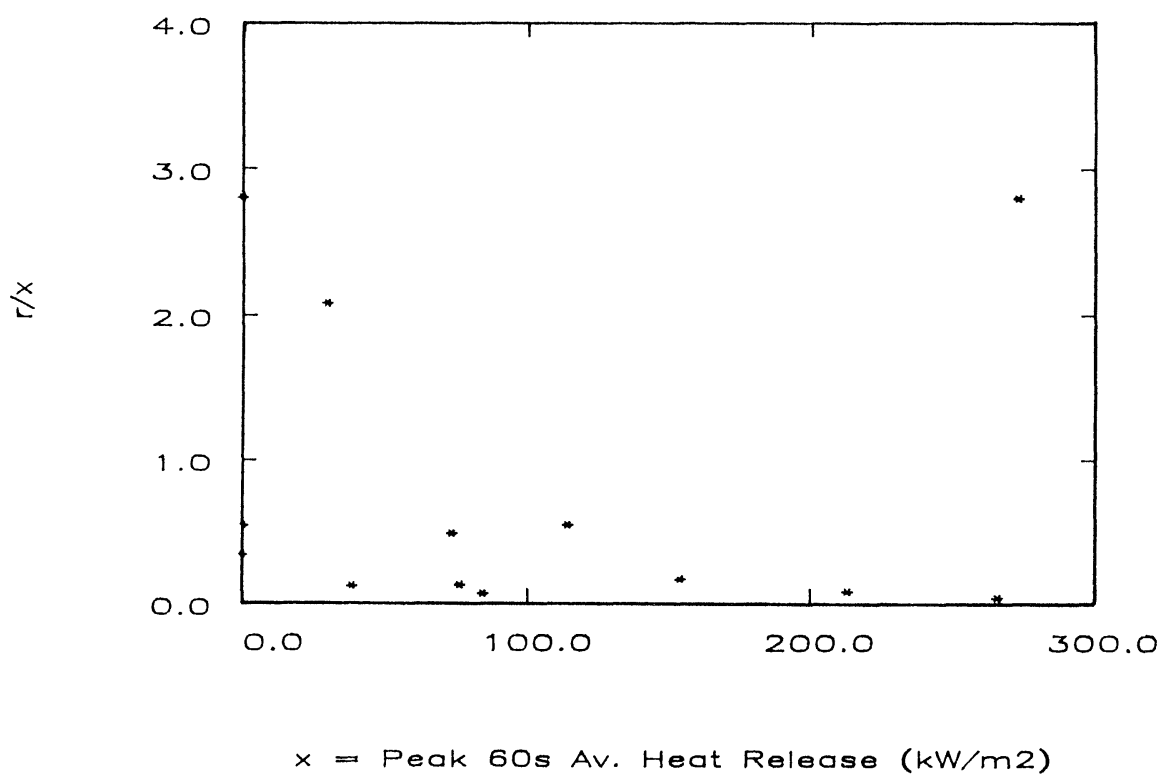

FIGURE 1 Relative reproducibility $(r / x)$ as a function of peak 60 s avge. heat release rate 


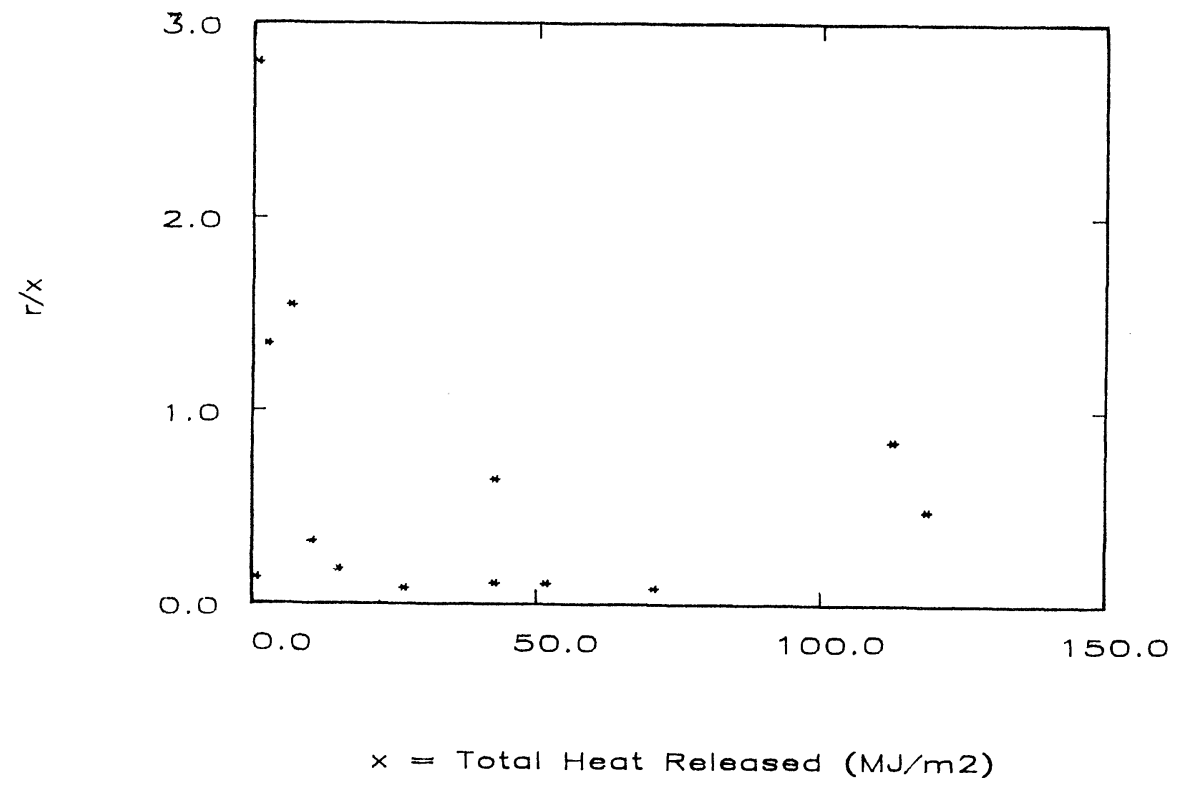

FIGURE 2 Relative reproducibility $(r / x)$ as a function of total heat released

\section{Experimental}

In this work, cone calorimetry was carried out on a series of materials chosen to test whether the thickness of the sample would have important effects on the data which might be used to assign combustibility classifications: Heat release rate and total heat content. Experiments were carried out using the procedure of ASTM E1354 at an imposed radiant flux of $75 \mathrm{~kW} / \mathrm{m}^{2}$ on a horizontally-mounted sample bounded with an edge frame. Data were collected with scan times of 2 seconds and the test duration was 20 minutes.

\section{A. Samples}

The samples tested were:

- Red oak: two thicknesses, $6.3 \mathrm{~mm}$ (.25 in) and $19 \mathrm{~mm}(.75 \mathrm{in})$.

- Acoustic ceiling tile: two thicknesses, $19 \mathrm{~mm}(3 / 4 \mathrm{in})$ and $25 \mathrm{~mm}$ (1 in)

- Two layered composites of differing thickness. Each sample consisted of a $0.6 \mathrm{~mm}$ sheet of polyethylene sandwiched between two pieces of acoustic tile. In one sample, both layers of tile were $9.4 \mathrm{~mm}$ ( $3 / 8 \mathrm{in})$ thick; in the other, the upper layer (i.e., the one exposed to the radiant flux) was $15.8 \mathrm{~mm}(5 / 8 \mathrm{in})$ and the lower layer (i.e., the one beneath the polyethylene sheet) was $9.4 \mathrm{~mm}(3 / 8 \mathrm{in})$. 


\section{B. Results}

The cone calorimeter measurements are displayed in Table 1. Also listed is the calculated total heat release expected from red oak ( $100 \%$ combustion efficiency assumed) at the tested thickness, and the ratio of the measured to the calculated values. For the composites, the calculated values of total heat released are for the polyethylene sheet alone. They were determined by subtracting the measured total heat of the appropriate thickness of acoustic tile from the value for the composite. The ratios of total heat release which appear for the composites are the ratios of the calculated value of the polyethylene sheet to a theoretical value of $22,000 \mathrm{MJ} / \mathrm{m}^{2}$ for $0.6 \mathrm{~mm}$ of pure polyethylene sheet.

Table 1: Cone Calorimeter Measurements on Samples of Varying Thickness ASTM E1354-93: $75 \mathrm{~kW} / \mathrm{m}^{2}$ imposed flux; horizontal orientation; 20 minute test

\begin{tabular}{|c|c|c|c|c|c|c|}
\hline \multirow[b]{2}{*}{$\underline{\text { Sample }}$} & \multirow[b]{2}{*}{ Thick.(mm) } & \multicolumn{2}{|c|}{$\begin{array}{l}\text { Heat Release Rate } \\
\qquad\left(\mathrm{kW} / \mathrm{m}^{2}\right)\end{array}$} & \multicolumn{3}{|c|}{ Total Heat Released $\left(\mathrm{MJ} / \mathrm{m}^{2}\right)$} \\
\hline & & Peak & 180 s avge & Measured & Calc. & Ratio \\
\hline Red Oak & 6.3 & 375 & 190 & 54,500 & 61,000 & .88 \\
\hline Red Oak & 19 & 190 & 131 & 123,000 & 183,000 & .66 \\
\hline Ac. tile & 19 & 19 & 15 & 7,700 & - & - \\
\hline Ac. tile & 25 & 23 & 15 & 9,300 & - & - \\
\hline $\begin{array}{l}\text { Composite } \\
\text { (Tile/PE/Tile }\end{array}$ & le) & 128 & 15 & 27,000 & $19,300^{1}$ & $.88^{2}$ \\
\hline $\begin{array}{l}\text { Composite } \\
\text { (Tile/PE/Tile }\end{array}$ & le) $16 / .6 / 9$ & 41 & 14 & 21,000 & $13,700^{1}$ & $.62^{2}$ \\
\hline
\end{tabular}

\section{Notes:}

1. Total heat of composite - total heat of acoustic tile.

2. Ratio of calculated total heat to theoretical value of $22,000 \mathrm{MJ} / \mathrm{m}^{2}$.

Comparison of the data for the two thicknesses of red oak shows an effect of thickness on all three measured parameters. Easiest to interpret is the effect of thickness on total heat release: a substantially lower fraction of the theoretical amount is produced by the thicker sample, presumably because its interior is somewhat better shielded from the imposed radiation.

In the thinner of the two composite samples, little protective effect is seen from the acoustic tile: A sharp peak is observed when the polyethylene sheet ignites and most of the expected 
heat from the sheet is realized. This is not the case for the thicker sample, however: both the peak heat release rate and the total heat released are considerably reduced by the shielding effect of the tile.

\section{Implications of Using the Cone Calorimeter to Classify Material Combustibility}

\section{A. Effects of Sample Thickness and Orientation}

The foregoing data demonstrate that, even when a very high imposed flux is used, thick samples can perform differently than thin ones. This means that any classification of materials using the cone should take into account the thickness of the material as it is intended to be used. One way to accomplish this in principle would be to collect data from the sample until no further heat is released instead of employing a test period of fixed duration. The test period would then be of the order of the thermal penetration time, $t_{p}$. The total heat measured is the product of $t_{p}$ and the average heat release rate, $\mathbf{Q}_{\mathbf{a v}}$. If the sample is completely consumed, the measured total heat is equal to the effective heat content; otherwise it is less.

$$
Q_{\mathrm{av}} t_{\mathrm{p}} \leqq \Delta \mathrm{H}_{\mathrm{e}} \rho \delta \mathrm{A}
$$

where: $\Delta \mathbf{H}_{\mathbf{e}}=$ effective heat of combustion; $\rho=$ sample density; $\delta=$ sample thickness and $\mathbf{A}=$ exposed sample area. For a thermally thick sample, the penetration time is defined as:

$$
t_{p}=\frac{\rho c \delta^{2}}{4 k}
$$

where $\mathbf{c}=$ heat capacity of the sample and $\mathbf{k}=$ its thermal conductivity. Thus,

$$
Q^{\prime \prime v v} \leqq \frac{4 \mathrm{k} \Delta \mathrm{H}_{\mathrm{e}}}{\mathrm{c} \delta} \text {. }
$$

Q" av, the measured average heat release rate per unit area, decreases with sample thickness. Figure 3 plots the equality for a solid sample of low conductivity and combustibility $\left(\Delta \mathrm{H}_{\mathbf{e}}=\right.$ $2000 \mathrm{~kJ} / \mathrm{kg} ; \mathbf{c}=1 \mathrm{~kJ} / \mathrm{kg} ; \mathbf{k}=.00005 \mathrm{~kW} / \mathrm{mK}$ )

Also shown are the upper and lower limits of reproducibility on $\mathrm{Q}_{\mathrm{av}}$, taken from reference 3. Current proposals ${ }^{9}$ are to assign the lowest level of combustibility to materials having maximum average heat release rates below $25 \mathrm{~kW} / \mathrm{m}^{2}$. As Figure 3 makes clear, it would be difficult to measure such a value reliably in samples thicker than about $15 \mathrm{~mm}$.

Cone calorimeter measurements may also be influenced by sample orientation. This is because when the sample is tested horizontally, the ash and char formed on the side exposed 


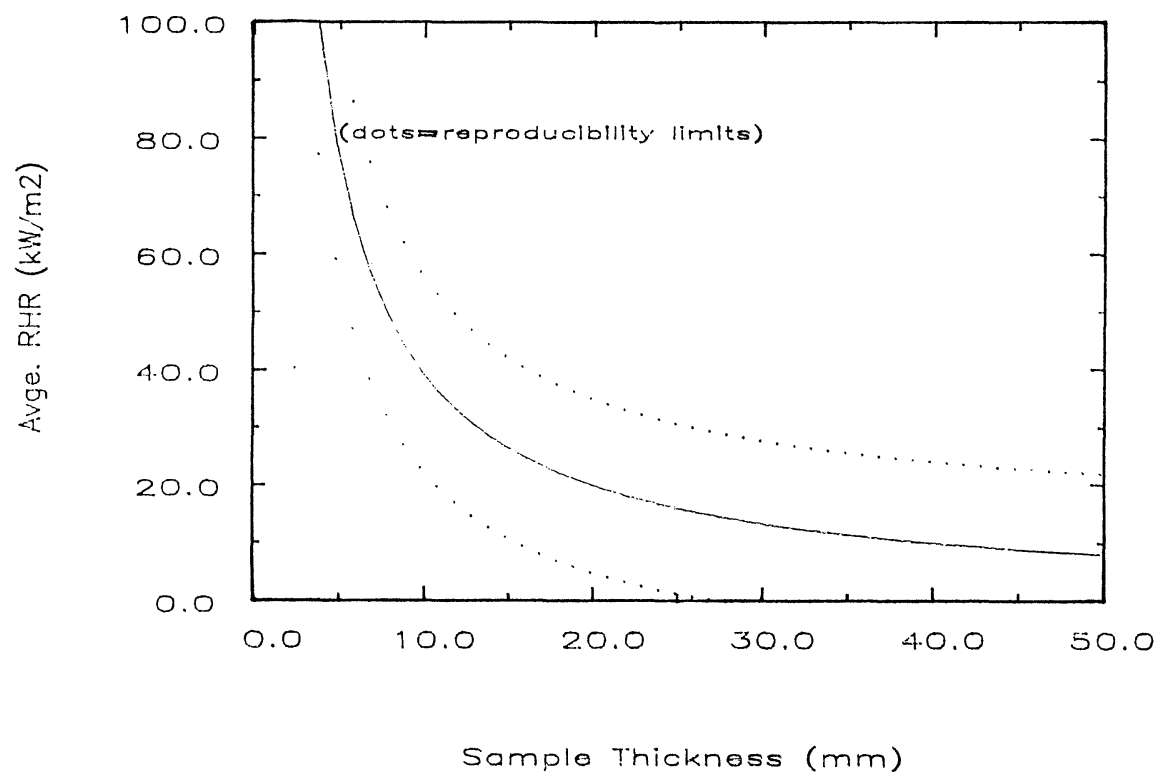

FIGURE 3 Dependence of average heat release rate of an insulating solid on thickness

to the heat can, as has been seen above, insulate its interior and retard thermal penetration. If the material is exposed vertically instead of horizontally, some of the protective material may fall away and, if it does, the measured heat release can be higher.

\section{B. Precision}

Two interlaboratory studies of the cone's precision have been conducted ${ }^{3,13}$. Both studies have characterized the method's reproducibility, $\mathrm{R}$ (defined as 2.8 times the standard deviation for reproducibility), as a linear function of the value of the measurement, $z$, i.e.,

$\mathbf{R}=\mathbf{a} z+\mathbf{b}$.

The value of $\mathrm{b}$ was found to be substantial, so that the relative reproducibility, $\mathrm{R} / z$, is poor at low values of $z$. One consequence of this fact is the limitation it imposes on sample thickness, as shown already in Figure 3. A more general problem is that the least combustible class of materials contemplated under a new classification system would have a limit in the neighbor-hood of $25 \mathrm{~kW} / \mathrm{m}^{2} 60$ s peak heat release and $10 \mathrm{MJ} / \mathrm{m}^{2}$ total heat released. At these levels of heat release, the uncertainty in the measurement would be larger than the entire range of the class $\left(\mathrm{R}=29 \mathrm{~kW} / \mathrm{m}^{2}\right.$ and $13 \mathrm{MJ} / \mathrm{m}^{2}$, respectively $\left.{ }^{3}\right)$. This greatly hampers facile use of the cone at low levels of combustibility. 


\section{Discussion}

In the interest of fairness, it would be a good idea if combustibility were measured on a continuous scale, with non-combustible items essentially at one end and conventional combustible materials at the other. Under the present system, if something fails the E136/ISO 1182 test by even the smallest amount it is usually treated as no different from conventional combustibles. A continuous scale of performance would be a major improvement. E136/ISO 1182 cannot be readily modified to accomplish such a change, so one must look somewhere else. The only two realistic choices among existing tests are the bomb calorimeter and the cone calorimeter.

\section{A. Comparison of Bomb and Cone Calorimeters: Suitability for Classifying Combustibles}

- Cone results are influenced by sample thickness (and, in some cases, probably orientation as well). Bomb results, which are expressed per unit of sample mass, are independent of sample size. Sample orientation is not an issue in the bomb.

- The precision of cone calorimeter data at low levels of combustibility is poor. The bomb calorimeter is capable of considerably higher precision ${ }^{14}$.

- Like the cone, the bomb puts combustibility on a continuous performance scale. Also like the cone, the bornb expresses results in a physically significant form, as a thermodynamic quantity in fact.

- It has been suggested that physical significance is important because combustibility can be used in developing a quantitative estimate of fire hazard. In principle this is quite true, but it is of little moment when working at the low end of the combustibility scale. NC-type materials/product produce so little heat that it is rarely more than just a few percent of any consequential thermal hazard. The mathematical fire models used in hazard assessment rely on simplifications and approximations which limit their accuracy to perhaps ten percent (although it may be possible to do better in certain situations) and the contribution from non-combustible items is unlikely to be of such a magnitude.

\section{B. Conversion Issues: Changing to a New Test}

One of the most troublesome practical issues in converting to a new test is where to draw the limits on each class. If the new test is the cone calorimeter, the criterion for $\mathrm{NC}$ will simply have to be selected with a degree of arbitrariness -- it can't be related back to E136/ISO 1182. The situation is somewhat clearer if the bomb is used. When the E136 test criteria were developed, the designers intended to allow a sample to pass which contained up to about three percent of combustible material (see commentary included in ASTM E136 ${ }^{1}$ ); that corresponds to about $1500-2000 \mathrm{~kJ} / \mathrm{kg}$. So, if the bomb were used in place of E136, there would be a natural crosswalk to a new test system. 


\section{Other Issues}

One practical issue is that the cone calorimeter can often test materials in a realistic manner, as they are intended to be used, while the bomb requires that they be homogenized. That means that products which depend on bulk effects, such as protective layers or thickness, for good performance may not do as well in the bomb as the cone.

When non-combustible behavior is really important however, one seeks to avoid significant heat production under the worst possible conditions, such as when the protective layer is breached or knocked off, not just under ideal conditions when everything is working as intended.

As was mentioned at the beginning of this paper, it is likely that there are some applications where non-combustibility is specified when in fact such a high level of protection isn't really needed. Having a test which puts combustibility on a continuous scale would, for the first time, give officials enough information to judge the actual hazard of a material/product instead of having to take an all-or-nothing approach. This is the best way to bring more realism to building regulations.

\section{References}

1. Standard Test Method for Behavior of Materials in a Vertical Tube Furnace at $750^{\circ} \mathrm{C}$. ASTM E136-93b, ASTM, Philadelphia, PA (1993).

2. Fire Tests-Building Materials-Non-combustibility test. ISO 1182: 1990E, International Organization for Standardization, Geneva (1990).

3. Standard Test Method for Heat and Visible Smoke Release Using an Oxygen Consumption Calorimeter. ASTM E1354-93, ASTM, Philadelphia (1993).

4. Fire Test-Reaction to Fire-Rate of Heat Release from Building Products. ISO 1182: 1995. International Organization for Standardization, Geneva (1995).

5. Richardson, L.R., Determining Degrees of Combustibility of Building MaterialsNational Building Code of Canada. Fire and Materials, 18, 99-106 (1994).

6. Standard Test Method for Gross Calorific Value of Coal and Coke by the Adiabatic Bomb Calorimeter. ASTM D2015-93, ASTM, Philadelphia, PA (1993).

7. Building Materials-Determination of Calorific Potential. ISO 1716, International Organization for Standardization, Geneva (1990).

8. Standard Test Method for the Potential Heat of Building Materials. NFPA 259, National Fire Protection Association, Quincy, MA (1991). 
9. Minutes of the BCMC Task Group on noncombustibility and degrees of combustibility, April 1995.

10. Hoover, J.R., results presented at Research Seminar, ASTM E5, Denver, 19 June, 1995; Product Safety Conference, Millbrae, CA, January 1995.

11. Houser, K.D., Variations in Heat Release Results and other Parameters Using the Cone Calorimeter, presented at Fire and Materials '95, 4th International Conference and Exhibit, Arlington, VA, November, 1995.

12. c.f. Standard Practice for Use of the Terms Precision and Bias in ASTM Test Methods (ASTM E177) and Standard Practice for Conducting an Interlaboratory Study to Determine the Precision of a Test Method (ASTM E691). ASTM, Philadelphia, PA.

13. Interlaboratory Test Program on ASTM E1354 Standard Test Method for Heat and Smoke Release Rates for Materials and Products using an Oxygen Consumption Calorimeter. International Fire Standards Project Report, ASTM Institute for Standards Research, Philadelphia, PA (1995).

14. Gross, D., and Natrella, M., Interlaboratory Comparison of the Potential Heat Test Method. ASTM Special Publication 464-1970. ASTM, Philadelphia, PA (1970).

\section{Acknowledgment}

The cone calorimeter measurements were carried out under the supervision of Dr. Pravin Gandhi of Underwriters Laboratories. His assistance and that of Mr. Robert Backstrom and Ms. Michelle Sluga are gratefully acknowledged. 
